\title{
Xanthogranulomatous oophoritis presenting as a pseudotumor of the ovary: a clinical dilemma
}

\author{
Dweep Jindal*, Meeta H. Mankad, Pariseema S. Dave, Anusha A. Kamath
}

Department of Gynaecologic Oncology, The Gujarat Cancer and Research Institute, Ahmedabad, Gujarat, India

Received: 23 March 2017

Accepted: 28 March 2017

\author{
*Correspondence: \\ Dr. Dweep Jindal, \\ E-mail: dweepjindal24@gmail.com
}

Copyright: () the author(s), publisher and licensee Medip Academy. This is an open-access article distributed under the terms of the Creative Commons Attribution Non-Commercial License, which permits unrestricted non-commercial use, distribution, and reproduction in any medium, provided the original work is properly cited.

\begin{abstract}
Background: Inflammatory Pseudotumor of ovary is a distinct benign entity characterized by the presence of spindle cells mixed with variable amount of lymphocytes and plasma cells. Female genital tract is an unusual location for xanthogranulomatous inflammation and if present usually involves the endometrium. xanthogranulomatous oophoritis is rare and only a handful of cases have been reported.

Methods: At The Gujarat Cancer and Research Institute, Ahmedabad; a Regional Cancer Centre we came across two cases of Xanthogranulomatous oophoritis, a rare clinical condition. In view of the rarity of the clinical entity, the cases are summarized and discussed.

Results: Xanthogranulomatous oophoritis is a rare clinical entity with very few reported cases. Its pathogenesis involves chronic inflammatory process of unknown origin. Pre-operative diagnosis has been challenging due to nonspecific presenting symptoms and radiological imaging. Characteristic microscopic picture includes presence of welldifferentiated spindle cells with variable amount of collagenous stroma and presence of inflammatory changes. Immunohistochemistry performed at our institute was found to be positive for CD 68, Vimentin and S-100 for xanthogranulomatous oophoritis.

Conclusions: Data from radiological imaging for extra genital xanthogranulomatous inflammation is being extrapolated to determine a pre-operative diagnosis for xanthogranulomatous oophoritis of the genital tract. However, no pathognomic radiological findings are defined at present making histopathological diagnosis the mainstay for diagnosis of this condition. Immunohistochemistry panel markers play a helpful role in the diagnosis when in doubt. Surgery is the definitive mode of treatment providing a good prognosis post operatively.
\end{abstract}

Keywords: Immunohistochemistry confirmation, Mimicking ovarian malignancy, Xanthogranulomatous oophoritis

\section{INTRODUCTION}

Inflammatory Pseudotumor of ovary is a distinct benign entity characterized by the presence of spindle cells mixed with variable amount of lymphocytes and plasma cells interspersed in extracellular collagen. This may mimic malignancy and hence termed as pseudotumor. The World Health Organization classifies inflammatory myofibroblastic tumor as a distinct borderline lesion with uncertainty as to whether it is reactive or neoplastic in nature. No definite cause for inflammatory pseudotumors has been identified thereby clouding the exact pathogenesis and etiology. ${ }^{1-3}$ Different theories put forward to explain the origin of this inflammatory state include chronic bacterial infection with E. coli, Proteus and Staphylococcus aureus, ineffective antibiotic therapy, endometriosis and intrauterine contraceptive device. They are characterized by microscopic findings of chronic inflammation. ${ }^{1,2}$ Presence of xanthogranulomatous inflammation is well documented in renal and biliary system. Female genital tract is an unusual location for xanthogranulomatous inflammation and if present usually 
involves the endometrium. ${ }^{2}$ Only a handful of cases of xanthogranulomatous oophoritis have been reported. ${ }^{2,3}$

\section{METHODS}

At The Gujarat Cancer and Research Institute, Ahmedabad; a Regional Cancer Centre we came across two cases of Xanthogranulomatous oophoritis, a rare clinical condition. In view of the rarity of the clinical entity, the cases are summarized and discussed below.

\section{RESULTS}

\section{Case 1}

A 17-year-old nulliparous, unmarried girl presented with lower abdominal pain and intermittent fever. She had regular menstrual cycles. She had no co existing surgical or medical co morbidity. On examination, a large mass filling the pelvic cavity was noted. She was evaluated for the pelvic mass and a CT Scan performed revealed a large solid cystic pelvic mass with internal septations extending into the abdomen superiorly, pouch of Douglas inferiorly and displacing the uterus anteriorly. Both ovaries were not seen separately from pelvic mass. Tumor markers performed were negative for germ cell tumor. CA 125 was marginally elevated to 71.96 units. Patient underwent surgical exploration with suspicion of ovarian neoplasm. During surgery, a large pelvic mass was noted, inseparable from both ovaries. The mass was seen to derive blood supply form bilateral infundibulopelvic ligament. Surgery included the removal of adnexal mass along with omental sampling. Histopathology of examined sections revealed sheets of foamy macrophages and lymphocytic-plasmocytic and eosinophilic infiltrate. No evidence of granuloma or malignancy was seen. The findings noted were suggestive of xanthogranulomatous inflammation.

\section{Case 2}

A 38-year-old married, nulliparous woman presented with lower abdominal pain predominantly on the left side. Previously she had undergone an abdominal myomectomy. On examination, a large firm to solid mass was felt in the lower abdomen arising from the pelvis, corresponding to 22 weeks of gestation in size. MRI performed showed a large heterogeneously enhancing illdefined irregular cystic mass with solid component seen in the left adnexal region. The mass was inseparable from the left ovary (Figure 2). In view of above findings with a suspicion of ovarian neoplasm, patient was subjected to a laparotomy. On laparotomy, a twelve-centimeter mass was noted arising from the left ovary, adherent to bowel and omentum. She underwent a left sided salpingooophorectomy. The mass was firm in consistency and on cut section appears greyish white. The specimen was subjected to frozen section due to pre-operative suspicion of malignancy. Frozen section revealed absence of malignancy in the sections studied and a fertility preserving surgery was performed. On histopathology sections showed sheets of foamy macrophages admixed with lymphocytes and plasma cells (Figure 1). No granulomas or presence of microorganism was noted giving an impression of xanthogranulomatous oophoritis. The specimen was subjected to five marker immunohistochemistry panel and was found to be positive for CD 68, Vimentin and S-100 confirming the diagnosis of Xanthogranulomatous inflammation.

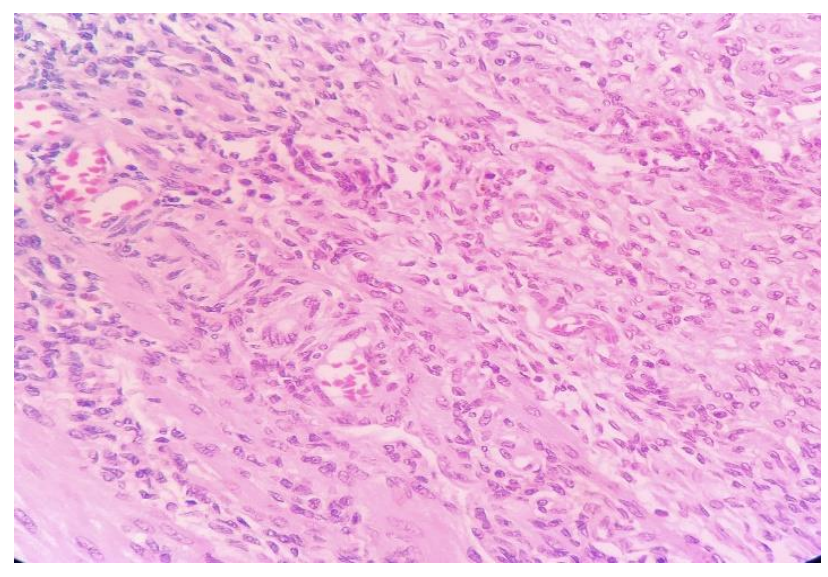

Figure 1: Sheets of foamy macrophages admixed with lymphocytes and plasma cells. No definite granulomas are seen.

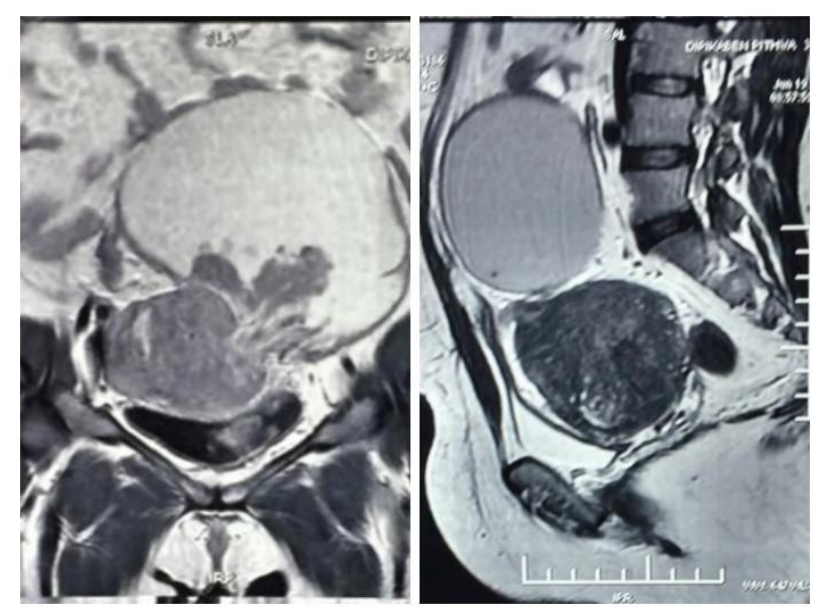

Figure 2: Large predominantly cystic mass with a solid nodule within seen infiltrating the uterus.

\section{DISCUSSION}

Xanthogranulomatous inflammation is a rare clinical condition. However, when encountered it occurs commonly in the lung, orbit, renal and biliary system. ${ }^{2,4}$ Its pathogenesis involves chronic inflammatory process of unknown origin.

This inflammatory process is commonly seen in childhood and early adulthood. In the handful of cases reported xanthogranulomaotus oophoritis presented in the reproductive age group (42-48 years). ${ }^{2,3}$ In the cases 
reported by us xanthogranulomatous oophoritis is seen in patients of age 17 and 38 respectively. Exact etiopathogenesis of this condition is unclear. Various theories are put forth as possible etiology of this clinical entity which include infection, ineffective antibiotic therapy, incomplete resolution of bacterial infection by phagocytes, endometriosis. ${ }^{1,2}$

Both the patients in our report have presented with lower abdominal pain and adnexal mass. In the first case patient also complained of low-grade intermittent fever thereby supporting the theory of an underlying infection being the cause of oophoritis. The common clinical features include diffuse lower abdominal pain, low-grade fever, and adnexal tenderness. ${ }^{1,2,4}$ Pre-operative diagnosis has been challenging due to non-specific presenting symptoms and radiological imaging. ${ }^{1}$ Pre-operative suspicion of malignancy results in referral of these cases to Oncology centers. Radiological imaging of our patients revealed adnexal masses of varying echoic nature and presence of solid cystic components. Date et al proposed that characteristic MR imaging findings of xanthogranulomatous oophoritis are multiple intramural nodules in a thickened wall with high signal intensity on T2-weighted images and low signal intensity on T1weighted images. No definitive imaging characteristics for xanthogranulomatous inflammation of female genital tract have been established unlike inflammatory changes of similar nature in renal or biliary system..$^{2,3}$

Despite attempts to obtain a pre-operative diagnosis, xanthogranulomatous oophoritis can be definitely diagnosed only on histopathology. ${ }^{3}$ Frozen section may be performed intra operatively which corroborates well with final histopathological diagnosis. Kalloli et al subjected the specimen to intra-operative frozen section, which was reported as benign inflammatory condition. Frozen section in the current case revealed a nonmalignant lesion, which guided the need for radical surgery. Characteristic microscopic picture of this clinical entity includes presence of well-differentiated spindle cells with variable amount of collagenous stroma and presence of inflammatory changes in the form of lymphocytes and plasma cells..$^{1,3}$ Both the cases reported above had a microscopic picture of sheets of foamy macrophages with presence of lymphocytic and plasma cell infiltrate.

Immunohistochemistry for xanthogranulomatous inflammation was found to be positive for Vimentin and CD 68. Immunohistochemistry performed at our institute was found to be positive for CD 68, Vimentin and S-100, providing further supportive evidence for diagnosis of xanthogranulomatous oophoritis. ${ }^{2,3}$ Management of a patient with xanthogranulomatous oophoritis is surgery as clinical presentation, radiological imaging and macroscopic observation are likely to misdiagnose a xanthogranulomatous lesion as a malignant process. ${ }^{3}$

\section{CONCLUSION}

Xanthogranulomatous oophoritis is a rare clinical entity with very few reported cases as per the literature reviewed. Data from radiological imaging for extra genital xanthogranulomatous inflammation is being extrapolated to determine a pre-operative diagnosis for xanthogranulomatous oophoritis of the genital tract. However, no pathognomic radiological findings are defined at present making histopathological diagnosis the mainstay for diagnosis of this condition. Immunohistochemistry panel markers play a helpful role in the diagnosis when in doubt. Surgery is the definitive mode of treatment providing a good prognosis post operatively.

\section{ACKNOWLEDGEMENTS}

Authors would like to thank the contribution of the Histopathology Department of the Institute under the guidance of Dr. Trupti Patel for providing the histopathology and immunohistochemistry data.

\section{Funding: No funding sources \\ Conflict of interest: None declared \\ Ethical approval: Not required}

\section{REFERENCES}

1. Tripathy S, Santhamani PM. Xanthogranulomatous oophoritis: A rare chronic inflammatory nonneoplastic ovarian pseudotumor. Int $\mathrm{J}$ Reprod Contracept Obstet Gynecol. 2016;5:3616-8.

2. Zhang XS, Dong HY, Zhang L1, Desouki MM, Zhao C. Xanthogranulomatous inflammation of the female genital tract: report of three cases. J Cancer. 2012;3:100-6.

3. Kalloli M, Bafna UD, Mukherjee G, Devi UK, Gurubasavangouda, Rathod PS. A rare Xanthogranulomatous Oophoritis presenting as ovarian cancer. Online J Health Allied Scs. 2012;11(2):11.

4. Pang SY, Aggarwal IM, Lim YK Xanthogranulomatous Salpingo-Oophoritis mimicking an ovarian malignancy-a series of 3 cases and review of literature. Obstet Gynecol Int J. 2016;5(3):162.

Cite this article as: Jindal D, Mankad MH, Dave PS, Kamath AA. Xanthogranulomatous oophoritis presenting as a pseudotumor of the ovary: a clinical dilemma. Int J Reprod Contracept Obstet Gynecol 2017;6:2098-2100. 